\begin{tabular}{l}
$\begin{array}{c}\text { Yanbu Journal } \\
\text { of }\end{array}$ \\
$\begin{array}{l}\text { Engineering } \\
\text { and Science }\end{array}$ \\
\hline \hline ISSN: $1658-5321$
\end{tabular}$\quad$ Vol. 6, April $2013(1434 \mathrm{H})$

\title{
HEAT SAVING IN EVAPORATIVE CRYSTALLIZATION BY INTRODUCING A HEAT PUMP
}

\author{
Zaid Ahmed Al-Anber \\ Department of Chemical Engineering, Faculty of Engineering Technology/Polytechnic Institute \\ Al-Balqa Applied University, Amman, Jordan
}

\begin{abstract}
In this work, based on theoretical calculations, had been made for suggesting methods of heating mother liquor in crystallizer for both kinds of evaporative crystallization process. These suggested designs aim to reduce and save the consumption of energy which consequently reduces the operational cost for the two types of crystallization. In the first type, it is found that the direct evaporative crystallization: when a heat pump was added to heat the medium (hot air), it had saved energy consumption range between $81 \%$ and $93 \%$ at different values of coefficient of performance (COP). While in the second type, the indirect evaporative crystallization, a heat pump was erected along the line containing the mixture of vapor coming from crystallizer and steam coming from jacket outlet, which resulted in a mixture acting as a heat source to the heat pump in order to preheat the inlet steam to the jacket. Calculations of the suggested design showed that the energy consumption can be saved within $8 \%$ to $26 \%$ at different COP values.
\end{abstract}

Keywords: Evaporative Crystallization, Energy Saving, Heat Pumps.

\section{INTRODUCTION}

Crystallization is a solid-liquid separation process in which mass transfer of a solute occurs from the liquid solution to a pure solid crystalline phase (process where solid particles are formed from a homogeneous phase)[1]. It is an important operation in the chemical industry as a method of purification and method of providing crystalline materials in the desired size range. In an energy-conscious environment, crystallization can offer substantial saving as a method of separation when compared with distillation, though it must be recognized that it is more costly to apply cooling than providing heating [2]. In crystallization, equilibrium is attained when the solution or mother liquor is saturated
[3].Crystallizers can be conveniently classified in terms of the method used to obtain deposition of particles by: cooling a concentrated hot solution; evaporating a solution; or evaporation under adiabatic cooling [2-5].

The concerns of energy consumption and environmental pollution urge researchers to work on the development of clean energy and the utilization of waste energy. Sorts of novel technologies were developed and the achievements were patented like a heat pump system. It utilizes the transformation between potential energy and thermal energy to realize the performance of heat pumping and refrigeration.Usually in such processes, two zones are present; a cooling zone, where heat must be removed from the process; and 
a heating zone, where heat must be added to the process.

The utilization of heat pumps in various chemical technological processes is considered as one of the promising methods for energy saving [6-8]. To our knowledge, the utilization of heat pump in a crystallizer has not been deeply reported yet for the purpose of energy saving. This work presents a theoretical analysis of the technical feasibility and the potential use of heat pump in the process of direct and indirect contact evaporative crystallization. Principle schemes of the process with insulation of heat pump and throttling valve are proposed and the corresponding calculations are performed .

\section{THEORY}

\subsection{YIELD AND HEAT EFFECTS IN CRYSTALLIZATION PROCESS}

In most cases, the process of crystallization is slow and the final mother liquor is in contact with a sufficiently large crystal surface so that the concentration of the mother liquor is substantially that of a saturated solution at the final temperature in the process.

In such cases it is normal to calculate the yield from the initial solution composition and the solubility of the material at the final temperature. If evaporative crystallization is involved, the solvent removed must be taken into account in determining the final yield.

The actual yield may be obtained from algebraic calculations or trial-and-error calculations when the heat effects in the process and any resultant evaporation are used to correct the initial assumption for the yield. The heat effects in a crystallization process can be computed by one of the following methods: A heat balance can be made in which individual heat effects such as sensible heats, latent heats, and the heat of crystallization can be combined into an equation for total heat effects. The second method is an enthalpy balance. This method can be made in which the total enthalpy of all leaving streams minus the total enthalpy of all entering streams is equal to the heat absorbed from external sources by the process.

In using the heat-balance method, it is necessary to make a corresponding mass balance, since the heat effects are related to the quantities of solids produced through the heat of crystallization. The advantage of the enthalpy-concentration-diagram method is that both heat and mass effects are taken into account simultaneously. This method has limited use because of the difficulty in obtaining enthalpy concentration data. This information has been published for only a few systems [3].

\subsection{DIRECT AND INDIRECT CONTACT EVAPORATIVE Crystallization}

The two processes of direct and indirect evaporation crystallization are basically used to separate mineral salts from their water solution, by partial evaporation using heating agents (hot air in direct method and steam in the indirect one) to reach over saturation state as shown in Figs. 1 and 2. When the crystals appear in the crystallizer, the formed slurry concentrated solution (mother liquor with crystals) is removed and fed to a separator to isolate the crystal [3]. The vapor out from the crystallizer goes to the atmosphere.

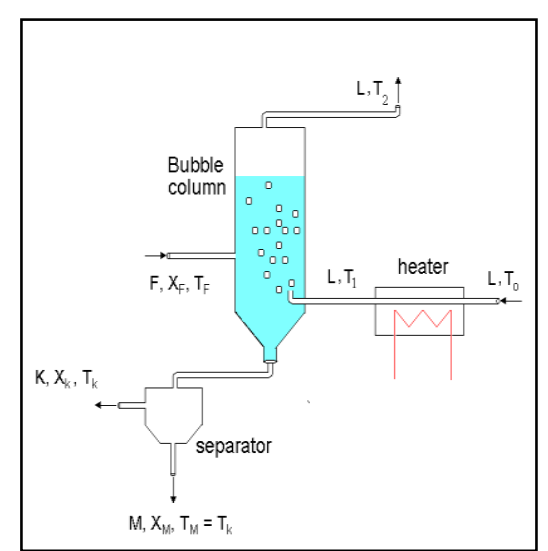

Fig.1. Principle scheme of direct contact evaporative crystallization. 


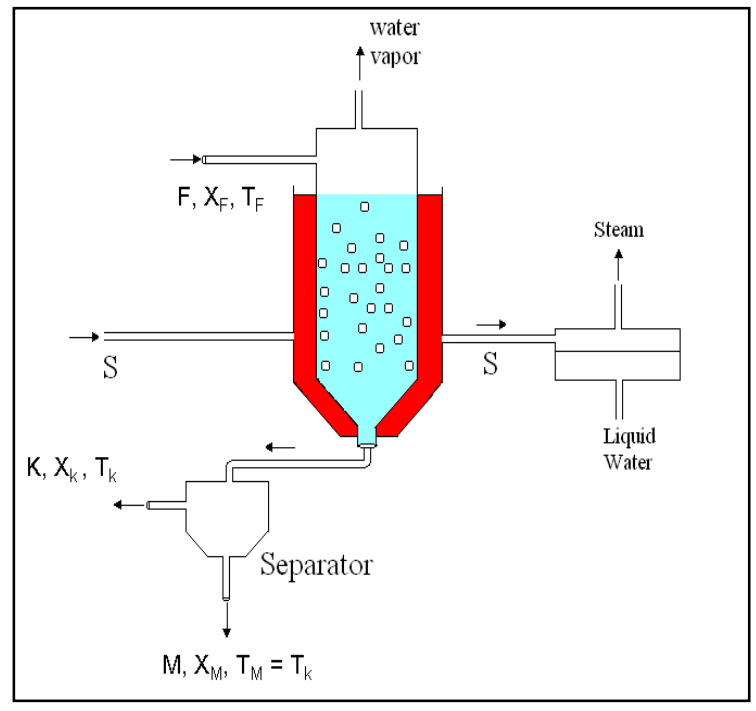

Fig.2. Principle scheme of indirect contact evaporative crystallization process.

This work is concentrated on the studying the feasibility of possible reduction in the heat demand for the process of direct and indirect contact evaporative crystallization by introducing heat pump in the process. For both processes, a model of sodium chloride solution or saline solution was used as a feed to the proposed process to extract salts minerals and production of pure desalinated water.

The introduction of a heat pump (closed cycle) is shown in Fig.3. The initial air at a temperature $\left(T_{0}=25{ }^{\circ} \mathrm{C}\right)$ is heated to a desired temperature $\left(T_{1}\right)$ by directing the air through the condenser of heat pump (in our case, the heater of the crystallizer). At the outlet of the bubble column crystallizer, the moisture content is removed by condensing it through passing over cooled surface of the heat pump evaporator (cooler). As shown in Fig. 4, we use heat pump system to achieve a coefficient of performance (COP) which enables us to have specific operating conditions for the process.

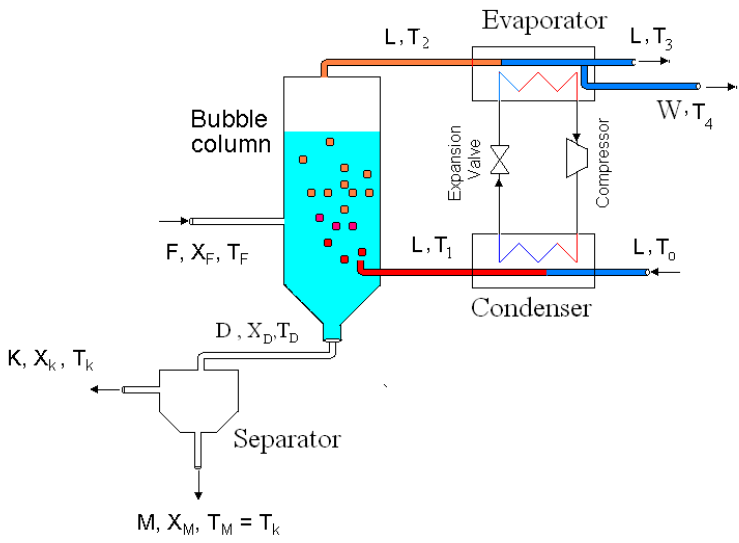

Fig.3. The process of direct contact crystallization with heat pump.

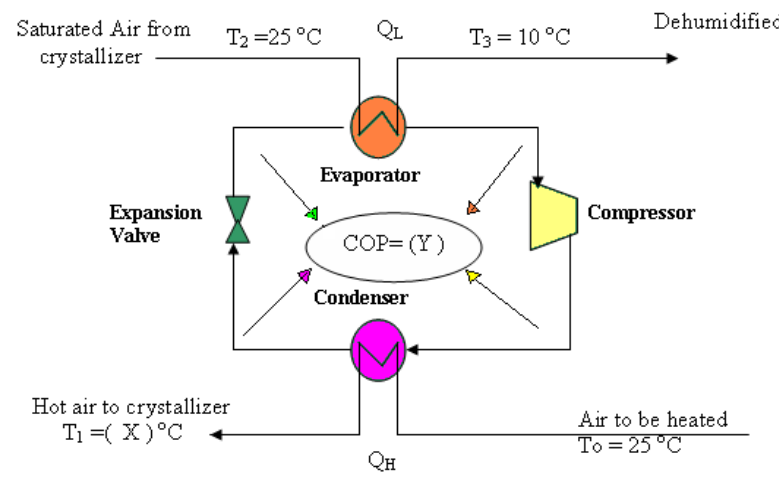

Fig.4. The operating conditions of the system and COP of heat pump.

\subsection{Material Balance for Direct Contact Evaporative Crystallization Process With HEAT PUMP}

As shown in Figure 1, hot air is contacted with the saline solution. The process is carried out in a bubble column crystallizer. Air is heated usually by electrical heater or by contacting with other heating agents. Hot air of a flow rate $(\mathrm{L})$ is brought into contact with solution (F) with a temperature and concentration $T_{F}, X_{F}$, respectively, in a bubble column causing the air to cool and some of liquid to evaporate. The air temperature will decrease from $T_{1}$ at the inlet of the column to $\mathrm{T}_{2}$ at the outlet. Consequently, the absolute and relative humidity will increase from $\alpha_{\mathrm{A} 1}$, $\alpha_{\mathrm{R} 1}$ to $\alpha_{\mathrm{A} 2}, \alpha_{\mathrm{R} 2}$ respectively. The enthalpy of air may remain constant if the contact in the bubble column is going under adiabatic 
conditions or it may change from $\mathrm{H}_{1}$ at the inlet to $\mathrm{H}_{2}$ at the outlet if other cooling conditions are applied. Distilled water of amount $(W)$ is obtained by dehumidifying the air in a condenser (the evaporator of heat pump). Formed slurry concentrated solution (D) is separated to crystal phase $(\mathrm{K})$ and mother liquor $(\mathrm{M})$.

The overall material balance is:

$F=K+M+L\left(\alpha_{A 2}-\alpha_{A 1}\right)$

The amount of evaporated solvent (water) is determined according to the difference of moisture content (air humidity) between the inlet and outlet as

$W=L\left(\alpha_{A 2}-\alpha_{A 1}\right)$

Substituting Eq. (2) into Eq. (1):

$F=K+M+W$

Also from

$D=K+M$

Then Eq. 4 becomes

$F=D+W$

Balance on solute can be expressed as:

$$
F X_{F}=D X_{D}+W X_{W}
$$

where $X_{F}, X_{D}$ and $X_{W}$ are the salts concentrations in feed, slurry concentration solution and condensate phases, respectively. Taking into account that evaporated water contains zero amount of solute $\left(\mathrm{X}_{\mathrm{W}}=0\right)$ then equation (6) becomes:

$F X_{F}=D X_{D}$

An expression for the amount of crystal phase as slurry can be obtained by solving Eq. (7)

$D=\frac{F X_{F}}{X_{D}}$

The amount of crystals formed can be calculated by knowing the efficiency of the separator.
2.4 Heat Balance OF DIRECT CONTACT Evaporative Crystallization WITH HeAT PUMP

The proposed process consists of direct contact evaporative crystallization with a heat pump shown in Fig. 3. The initial air with a temperature $\left(T_{0}\right)$ is heated to a desired temperature $\left(T_{1}\right)$ by directing the air through the condenser (heater). At the outlet of the bubble column crystallizer the moisture content is removed by condensing it when passing over the cooled surface of the evaporator. The amount of heat that must be added to the air is the same or less than amount of heat that must be delivered by heat pump in the condenser and can be calculated as:

$$
Q_{H}=L\left(H_{1}-H_{o}\right)
$$

Evaporator energy balance is:

$$
Q_{L}=L\left(H_{3}-H_{2}\right)=L C_{\text {pair }}\left(T_{3}-T_{2}\right)
$$

The measure of performance of a heat pump is expressed in terms of coefficient of performance $\mathrm{COP}_{\mathrm{HP}}$, defined as:

$C O P_{H P}=\frac{Q_{H}}{W_{i n}}$

By applying energy balance on the heat pump

$W_{\text {in }}=Q_{H}-Q_{L}$

or

$Q_{H}=W_{i n}+Q_{L}$

An expression for the applied work can be obtained by solving Eq. (11) and Eq. (12) together:

$W_{i n}=\frac{Q_{L}}{\left(C O P_{H P}-1\right)}$

2.5 ECONOMIC ANALYSIS FOR A DiRECT CONTACT EVAPORATIVE CRYstallization WITH HEAT PUMP

To evaluate the feasibility of introducing a heat pump into a direct contact evaporative 
crystallization, it is required to estimate the cost of heating for ordinary system and compare it with a system that includes heat pump. Depending on the operating conditions; i.e., the source of heating medium used in the heater to heat up the initial air, the total operating cost $(\$ / \mathrm{hr})$ can be estimated as:

$$
E_{S}=Q_{H} \times D_{S}+E_{\text {heater }}
$$

Where $D_{S}$ is the price of heating source $(\$ / \mathrm{kJ})$ in case of using steam, $E_{\text {heater }}(\$ / h)$ is the cost of heating agent used in the heater.

$$
E_{E}=Q_{H} \times D_{E}
$$

where $D_{E}$ is the price of heating source $(\$ / \mathrm{kWh})$ in case of using electricity.

The cost of the process with a heat pump consists only of the cost of the electrical power supplied to the compressor which is estimated as:

$$
P_{a}=W_{i n} / \eta
$$

Where $\mathrm{P}_{\mathrm{a}}$ is the actual electrical power required for a compressor and $\eta$ is the overall efficiency of the compressor which ranges from 65 to $75 \%$ [10]. The operating Cost $(\$ / \mathrm{hr})$ of the system with a heat pump is:

$$
E_{H}=P_{a} \times D_{E}
$$

The resulted saving factor by introducing a heat pump to a system of direct contact evaporative crystallization is defined by:

$S_{E}=\left(1-\frac{E_{H}}{E_{S, E}}\right) \times 100 \%$

Where $E_{H}$ is the total operating cost of heat pump in $(\$ / h r)$ And $E_{S}, E$ in case of using steam or electricity, respectively.

\subsection{ENERgY RECYCLING AND RECOVERY IN CASE OF INDIRECT CONTACT EVAPORATIVE Crystallization}

For indirect evaporative process we studied the feasibility of energy recovery process; i.e., the outlet steam that exits from crystallizer and jacket that would normally be wasted, converting it into thermal energy by addition of a heat pump on outlet vapor line and steam in three schemes:

1. The inlet to the evaporator is the outlet vapor from the crystallizer. (Figure 5)

2. The inlet to the evaporator is the outlet steam from the jacket. (Figure 6)

3. The inlet to the evaporator is the mixture made of the outlet vapor from crystallizer and steam outlet from the jacket (Figure 7).

In the three schemes, the heat pump makes a closed system, the condenser of the heat pump connected to the inlet steam line to make a preheating of the steam inlet of the jacket, then the steam completes heating to the required temperature using a heater with low pressure steam.

For the first scheme (i.e., Fig. 5), the superheated steam with temperature $\left(\mathrm{T}_{2}=\right.$ $150{ }^{\circ} \mathrm{C}$ ) is fed to the jacket to be cooled and give the evaporative crystallizer the required heat to realize the crystallization state and it then leaves the jacket at temperature $\mathrm{T}=25^{\circ} \mathrm{C}$. On the other hand, the vapor resulted by crystallization process out of the crystallizer is at temperature almost equal to $70^{\circ} \mathrm{C}$. The outlet vapor from the crystallizer is sucked to the evaporator of the heat pump. The condenser of heat pump acts as a preheating medium for the inlet stream of the jacket. 


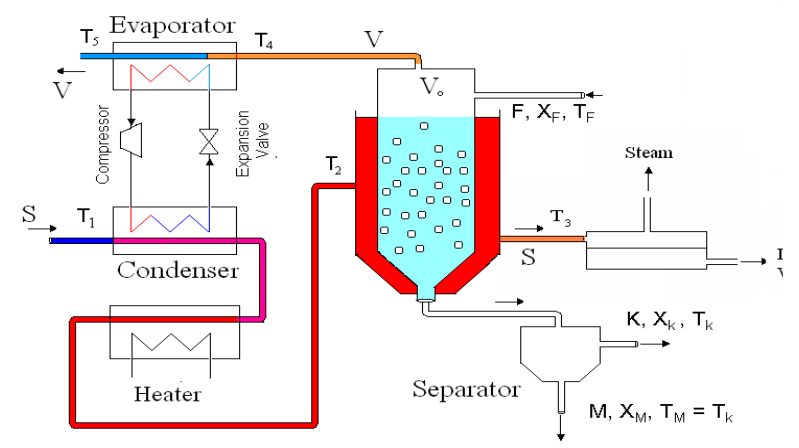

Fig.5. The process of indirect contact crystallization with heat pump when the feed to heat pump evaporator is Vo.

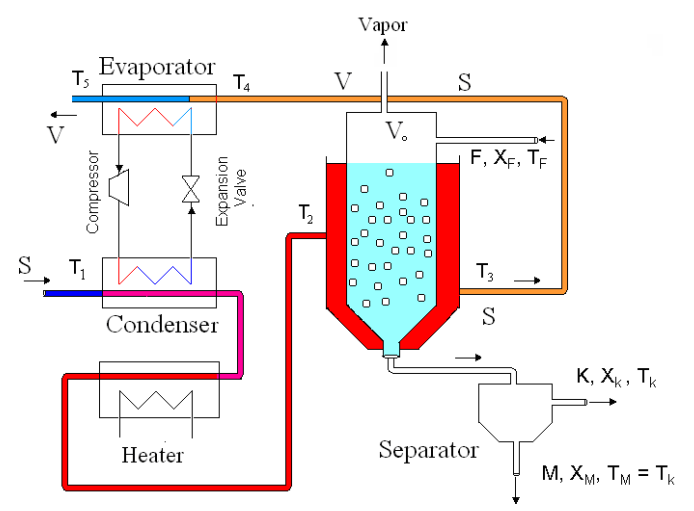

Fig.6. The process of indirect contact crystallization with heat pump when the feed to heat pump evaporator is $S$.

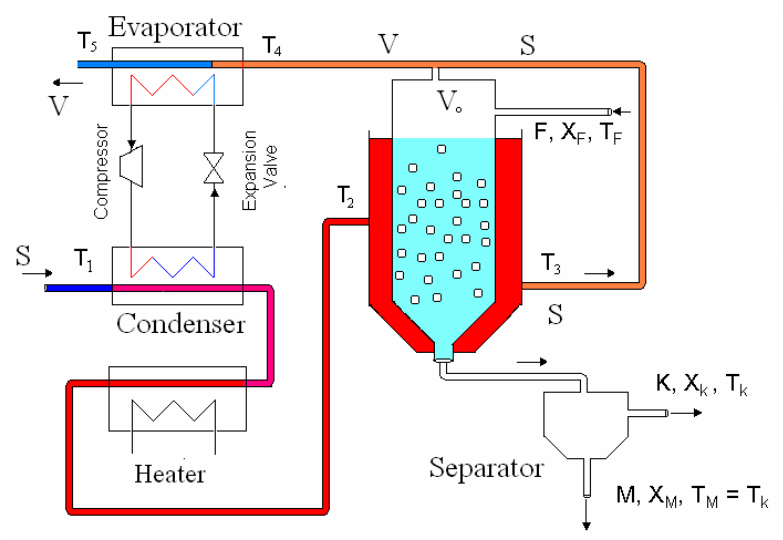

Fig. 7. The process of indirect contact crystallization with heat pump when the feed to heat pump evaporator consists of $S$ and Vo.

For the second scheme (i.e., Fig. 6), the superheated steam with temperature $\left(\mathrm{T}_{2}=\right.$ $150^{\circ} \mathrm{C}$ ) is fed to the jacket to be cooled and give the evaporator crystallizer the required heat to realize the crystallization state and it then leaves the jacket at temperature $\mathrm{T}=25^{\circ} \mathrm{C}$. The vapor resulted by crystallization process out of the crystallizer is at temperature almost equal to $70^{\circ} \mathrm{C}$. The outlet steam from the jacket is sucked to the evaporator of the heat pump. The condenser of heat pump acts as a preheating medium for the inlet stream of the jacket.

For the third scheme (i.e., Fig. 7), the superheated steam with temperature $\left(\mathrm{T}_{2}=\right.$ $150{ }^{\circ} \mathrm{C}$ ) is fed to the jacket to be cooled and give the evaporator crystallizer the required heat to realize the crystallization state and it then leaves the jacket at temperature $\mathrm{T}=25^{\circ} \mathrm{C}$. The vapor resulted by crystallization process out of the crystallizer isat temperature almost equal to $70^{\circ} \mathrm{C}$. The two outlet streams from jacket and crystallizer are mixed together and sucked to the evaporator of the heat pump. The condenser of the heat pump acts as preheating medium for the inlet stream of the jacket.

\subsection{MATERIAL BALANCE FOR INDIRECT CONTACT Evaporative Crystallization Process by AdDing Heat PumP}

As shown in Figure 7, steam is initiallyheated by the condenser of the heat pump and then heated by electrical heater or by contacting with other heating agents to reach the desired temperature $\left(T_{2}\right)$. A superheated steam with flow rate $(S)$ is fed to the jacket that heats the solution (F) with a temperature and concentration $\mathrm{T}_{\mathrm{F}}, \mathrm{X}_{\mathrm{F}}$, respectively, in a evaporative column, where some of the liquid evaporates and the steam as a result will cool (the superheated steam temperature will decrease), the outlet steam from jacket is mixed with the steam out of the crystallizer to give a stream with flow rate $(\mathrm{V})$ and temperature $\left(\mathrm{T}_{4}\right)$. The resultant stream is fed to the evaporator of the heat pump, where the temperature will drop from $\mathrm{T}_{4}$, at the inlet of the evaporator, to $T_{5}$, at the outlet. This drop in temperature is accompanied by a release of a definite amount of heat $\mathrm{Q}_{\mathrm{L}}$. At a given COP and known amount of $Q_{\mathrm{I}}$, we can estimate the amount of heat $\mathrm{Q}_{\mathrm{H}}$ used for preheating the 
steam inlet to the jacket by the condenser of the heat pump followed by a continued heating by electrical heater or by contacting with another heating agent to reach $T_{2}$ that facilitates the crystallization process.

The overall material balance is:

$$
F=K+M+\mathrm{V}_{\mathrm{o}}
$$

Balance on the solute can be expressed as:

$$
F X_{F}=k X_{k}+M X_{M}+\mathrm{V}_{\mathrm{o}} X_{v o}
$$

Where $\mathrm{X}_{\mathrm{F}}, \mathrm{X}_{\mathrm{K}}, \mathrm{X}_{\mathrm{M}}$, and $\mathrm{X}_{\mathrm{Vo}}$ are the salt concentration in feed, crystal, mother liquor and vapor phase, respectively. Taking into account that evaporated water contains zero amount of solute $\left(\mathrm{X}_{\mathrm{Vo}_{\mathrm{o}}}=0\right)$ Then equation $(21)$ becomes:

$$
F X_{F}=k X_{k}+M X_{M o}
$$

Total material balance

$$
D=K+M
$$

Component material balance

$$
D X_{F}=K X_{K}+M X_{M}
$$

Then eq. (20) becomes

$$
F=D+V_{o}
$$

Balance on the solute can then be expressed as:

$$
F X_{F}=D X_{D}+\mathrm{V}_{\mathrm{O}} X_{v}
$$

An expression for the amount of crystal phase can be obtained by solving Eq. (25) and Eq. (26) together and as we know $X_{v}=0$ then

$\frac{V_{O}}{F}=1-\frac{X_{F}}{X_{D}}$

The total steam fed to the evaporator of heat pump is:

$V=V_{o}+S$

\subsection{HEAT BALANCE FOR INDIRECT CONTACT Evaporative Crystallization With a Heat PUMP}

By applying energy balance on the steam that is fed to the jacket [which scheme; 1,2, or 3]
$S h_{2}-\mathrm{SH}_{3}=\mathrm{VH}_{v o}$

and then $S$ :

$S=\frac{V_{o} H_{v o}}{h_{2}-h_{3}}$

The amount of heat generated from the evaporator can be calculated as:

1 - If the inlet to the evaporator is stream, $V_{0}$ :

$Q_{L}=Q_{v}=V_{o}\left(h_{4}-h_{5}\right)$

2-If the inlet to the evaporator is stream $S$ :

$Q_{L}=Q_{s o}=S\left(h_{4}-h_{5}\right)$

3-If the inlet to the evaporator is stream $\mathrm{V}(\mathrm{S}$ $\left.+\mathrm{V}_{\mathrm{o}}\right)$ :

$Q_{L}=Q_{v}+Q_{s o}$

The measure of performance of a heat pump is expressed in terms of coefficient of performance $\mathrm{COP}_{\mathrm{HP}}$, defined as:

$C O P_{H P}=\frac{Q_{H}}{W_{i n}}$

By applying energy balance on the heat pump

$W_{\text {in }}=Q_{H}-Q_{L}$

and

$Q_{H}=W_{i n}+Q_{L}$

An expression for the amount of work can be obtained by solving Eq. (34) and Eq. (36) :

$$
W_{\text {in }}=\frac{Q_{L}}{\left(C O P_{H P}-1\right)}
$$

As expression for the amount of heat that required increasing temperature $T_{2}$ to $T_{3}$ using heater (without heat pump):

$Q_{S}=S\left(h_{2}-h_{3}\right)$

The makeup amount of heat (using heater) which must be added after the heat pump, $\mathrm{Q}_{\mathrm{J}}$ can calculate by:

$Q_{J}=Q_{s}-Q_{H}$ 


\subsection{ECONOMIC ANALYSIS FOR INDIRECT CONTACT evaporative Crystallization Process with Heat PUMP}

To evaluate the feasibility of adding heat pump compressor on outlet steam line (from crystallizer) in evaporative crystallization as shown in Fig.8, it is required to estimate the cost of heating for ordinary system and compare it with a system that includes the heat pump. Depending on the operating conditions; i.e., the source of heating medium used in the heater to heat up the inlet steam temperature (fed to the jacket), the total operating cost $(\$ / \mathrm{hr})$ can be estimated as:

$\Phi_{S}=Q_{s} \times D_{s}+\Phi_{\text {heater }}$

where $D_{S}$ is the price of heating source $(\$ / \mathrm{kJ})$ in case of using steam, $\Phi_{\text {better }}:(\$ / \mathrm{h})$ is the cost of heating agent used in the heater, $\Phi_{\text {heater }}$, expressed in $\$ / \mathrm{h}$, is the cost of heating agent divided by its life time, expressed in $h$. The cost of the process with a heat pump consists only from the cost of the electrical power supplied to the compressor which estimated as:

$$
P_{a}=W_{i n} / \eta
$$

Where $\mathrm{P}_{\mathrm{a}}$ is the actual electrical power required for a compressor and $\eta$ is the overall efficiency of the compressor which ranges from 65 to $75 \%$ [10]. The operating Cost $(\$ / h r)$ of the electrical power supplied to the compressor, which is estimated as:

$$
\Phi_{H}=P_{a} \times D_{E}
$$

The operating cost $(\$ / \mathrm{hr})$ of the heat that is needed after heat pump preheating (i.e., heating make up) which estimated as:

$$
\Phi_{J}=Q_{J} \times D_{s}+\Phi_{\text {heater }}
$$

The total operating Cost $(\$ / h r)$ of the process with a heat pump on outlet vapor line (from crystallizer) is summation of the cost of the electrical power supplied to the compressor and the cost of heating make up steam, which can be estimated as:

$\Phi_{T}=\Phi_{J}+\Phi_{H}$

The resulted saving factor by indirect contact evaporative crystallization is defined by:

$S_{E}=\left(1-\frac{\Phi_{T}}{\Phi_{s}}\right) \times 100 \% \quad$ B

Where $\Phi_{\mathrm{T}}$ the total operating cost of add compressor on outlet steam line (from crystallizer) in $(\$ / h r)$ and $\Phi_{s}$ the total operating cost $(\$ / h r)$ without heat pump.

\section{RESULTS AND DISCUSSIONS}

\subsection{Case one: Direct Contact Evaporative Crystallization with Heat PumP}

In this study, we use heat pump system to make a relation between coefficient of performance (COP) and initial temperature of the hot air fed to the crystallizer at constant humidity, then by quantifying this relation we can see the effect of introducing heat pump on the operational energy saving in the process of direct contact evaporative crystallization. The following assumptions were proposed:

1. Steady state, steady flow operation.

2. Potential and kinetic energy effects are negligible.

3. No chemical reaction.

4. Adiabatic compression efficiency is equal 0.7 .

5. The price of electricity and low pressure steam for heating (LPS) are estimated to be $0.05(\$ / \mathrm{kW} . \mathrm{h})$ and $3.17 \times 10^{-6}(\$ / \mathrm{kJ})$ respectively, and the cost of heating agent used in heater $=0.33 \$ / \mathrm{kJ}$.[7].

6. The used high-efficiency heat pump manufactured has COP of (2.3-5) in the heating mode [6].

7. The used basis for calculation is listed in Table (1). 
TABle (1) : BASIS For CALCUlatios $[1,4]$

\begin{tabular}{|l|l|l|l|l|}
\hline $\mathrm{F}$ & $100 \mathrm{~kg} / \mathrm{hr}$ & & $\mathrm{C}_{\mathrm{p}}$ air & $1.03 \mathrm{KJ} / \mathrm{kg} \mathrm{K}$ \\
\cline { 1 - 1 } $\mathrm{X}_{\mathrm{f}}$ & 0.36 & $\mathrm{a}_{\mathrm{A} 2} @ \mathrm{~T}_{2}$ & $\begin{array}{l}0.022 \\
\text { water } / \mathrm{kg} \text { dry air }\end{array}$ \\
\hline $\mathrm{T}_{2}$ & $25^{\circ} \mathrm{C}$ & $\mathrm{a}_{\mathrm{R} 1}$ & $20 \%$ \\
\hline $\mathrm{T}_{3}$ & $10^{\circ} \mathrm{C}$ & $\mathbf{\alpha}_{\mathrm{R} 2}$ & $100 \%$ \\
\hline $\mathrm{L}$ & $600 \mathrm{Kg} / \mathrm{hr}$ & & \\
\hline
\end{tabular}

The calculations of heat accepted by evaporator, $Q_{L}$, Work input into heat pump
Win, Heat generated by condenser $\mathrm{Q}_{\mathrm{H}}$, Inlet air temperature $T_{1}$, Mass flow rate of water $\mathrm{W}$, Mass flow of slurry concentrated solution $\mathrm{D}$, Slurry concentration $\mathrm{X}_{\mathrm{D}}$, and Air moisture content at $T_{1}$ are presented in Table $2 \mathrm{~A}$.

While the calculations of total operating cost without heat pump (heating by steam) $\mathrm{E}_{\mathrm{S}}$, Total Operating cost without heat pump (heating by electricity) $\mathrm{E}_{\mathrm{E}}$, Total operating cost with heat pump $\mathrm{E}_{\mathrm{H}}$, Saving factor based on electrical heating $S_{\mathrm{EE}}$, and saving factor based on steam heating $\mathrm{E}_{\mathrm{ES}}$ are presented in Table 2B.

TABLE 2A: MATERIAL AND ENERGY RESULTS OF DIRECT CONTACT EVAPORATIVE CRYSTALLIZATION WITH HEAT PUMP

\begin{tabular}{|l|l|l|c|c|c|c|c|c|}
\hline COP & $\begin{array}{c}\mathrm{Q}_{\mathrm{L}} \\
(\mathrm{KJ} / \mathrm{hr})\end{array}$ & $\begin{array}{c}\text { Win } \\
(\mathrm{KJ} / \mathrm{hr})\end{array}$ & $\begin{array}{c}\mathrm{Q}_{\mathrm{H}} \\
(\mathrm{KJ} / \mathrm{hr})\end{array}$ & $\begin{array}{c}\mathrm{T}_{1} \\
(\mathrm{~K})\end{array}$ & $\begin{array}{c}\mathrm{W} \\
(\mathrm{Kg} / \mathrm{hr})\end{array}$ & $\begin{array}{c}\mathrm{D} \\
(\mathrm{Kg} / \mathrm{hr})\end{array}$ & $\mathrm{X}_{\mathrm{D}}$ & $\mathrm{\alpha}_{\mathrm{A} 1}$ \\
\hline 2.3 & 9270 & 7130.8 & 16400.8 & 324.7 & 1.8 & 998.2 & 0.360649 & 0.019 \\
\hline 2.5 & 9270 & 6180 & 15450 & 323.2 & 3 & 997 & 0.361083 & 0.017 \\
\hline 3 & 9270 & 4635 & 13905 & 320.7 & 3.6 & 996.4 & 0.361301 & 0.016 \\
\hline 3.5 & 9270 & 3708 & 12978 & 319.2 & 3.6 & 996.4 & 0.361301 & 0.016 \\
\hline 4 & 9270 & 3090 & 12360 & 318.2 & 4.2 & 995.8 & 0.361518 & 0.015 \\
\hline 4.5 & 9270 & 2648.6 & 11918.6 & 317.4 & 5.4 & 994.6 & 0.361955 & 0.013 \\
\hline 5 & 9270 & 2317.5 & 11587.5 & 316.9 & 6.6 & 993.4 & 0.362392 & 0.011 \\
\hline
\end{tabular}

TABLE 2B: THE COST AND SAVING FACTOR RESULTS OF DIRECT CONTACT EVAPORATIVE CRYSTALLIZATION WITH HEAT PUMP

\begin{tabular}{|r|c|c|c|c|c|}
\hline COP & $\begin{array}{c}\mathrm{Es} \\
(\$ / \mathrm{hr})\end{array}$ & $\begin{array}{c}\mathrm{E}_{\mathrm{E}} \\
(\$ / \mathrm{hr})\end{array}$ & $\begin{array}{c}\mathrm{E}_{\mathrm{H}} \\
(\$ / \mathrm{hr})\end{array}$ & $\mathrm{S}_{\mathrm{EE}}$ & $\mathrm{S}_{\mathrm{Es}}$ \\
\hline 2.3 & 0.38199 & 0.227788 & 0.069327 & 69.5652 & 81.85114 \\
\hline 2.5 & 0.378977 & 0.214583 & 0.060083 & 72.0000 & 84.14589 \\
\hline 3 & 0.374079 & 0.193125 & 0.045063 & 76.6667 & 87.95374 \\
\hline 3.5 & 0.37114 & 0.18025 & 0.03605 & 80.0000 & 90.28669 \\
\hline 4 & 0.369181 & 0.171667 & 0.030042 & 82.5000 & 91.86262 \\
\hline 4.5 & 0.367782 & 0.165536 & 0.02575 & 84.4444 & 92.99857 \\
\hline 5 & 0.366732 & 0.160938 & 0.022531 & 86.0000 & 93.85621 \\
\hline
\end{tabular}


The relationship between the inlet air temperature and the slurry concentration is shown in Figure 8. It can be seen that as the inlet air temperature decreases, the concentration of slurry increases. This can be understood by the fact that at constant flow, the humidity of air flow decreases by lowering temperature and then causes to maximize the ability of air to carry water from solution.

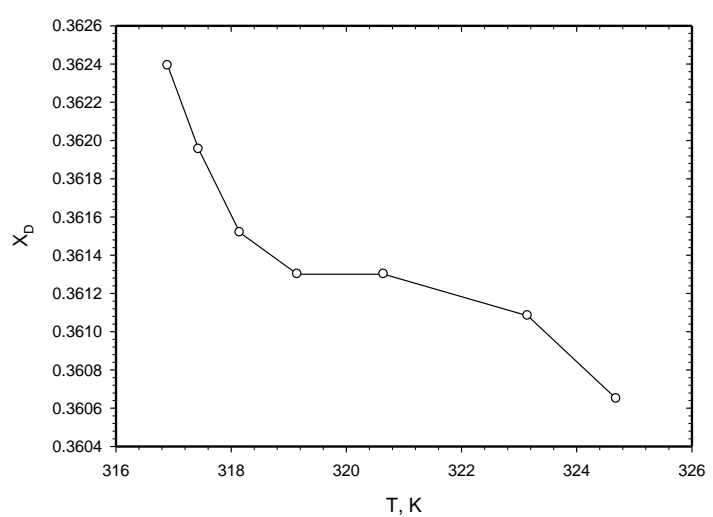

Fig.8. Relation between inlet air temperature to crystallizer and slurry concentration.

Figures 9 and 10 show that increasing of the value of COP results in increasing of the concentration of the produced slurry. It can be explained by the fact that the relationship between COP and the temperature of inlet air is inversely proportional.

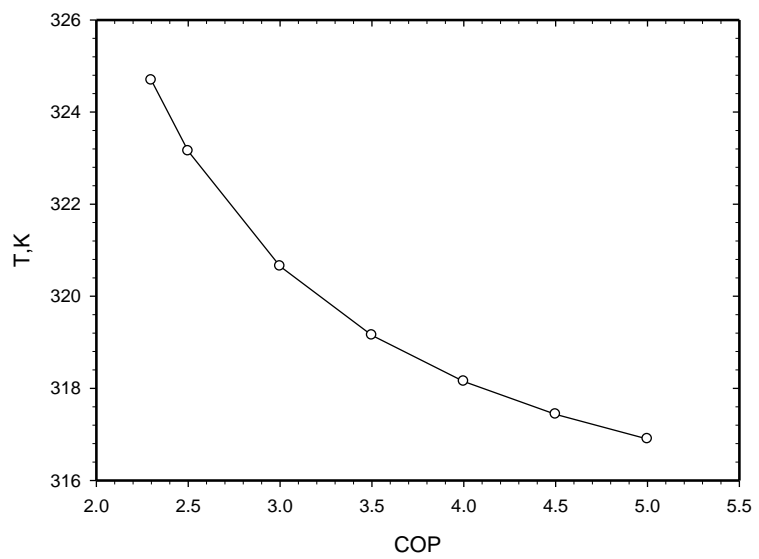

Fig.9. The coefficient of performance (COP) effect on inlet air temperature to crystallizer $\left(\mathrm{T}_{1}\right)$.

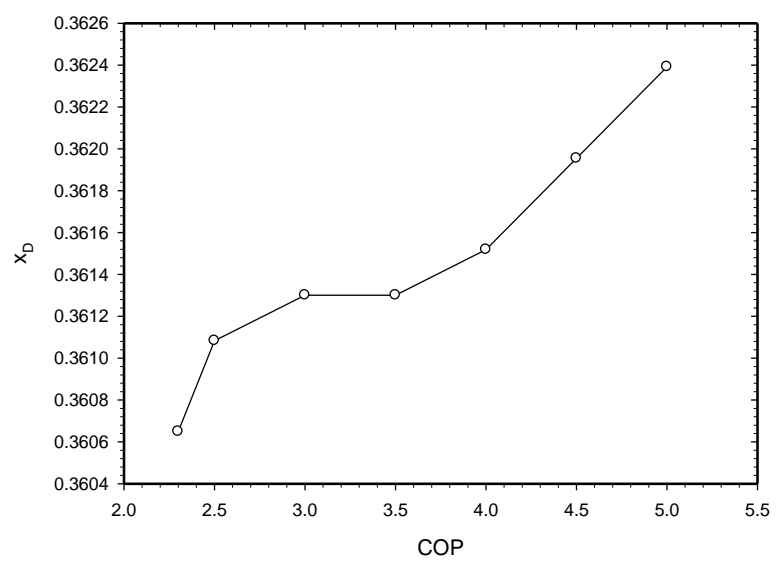

Fig.10. Effect coefficient of performance (COP) on produced slurry concentration.

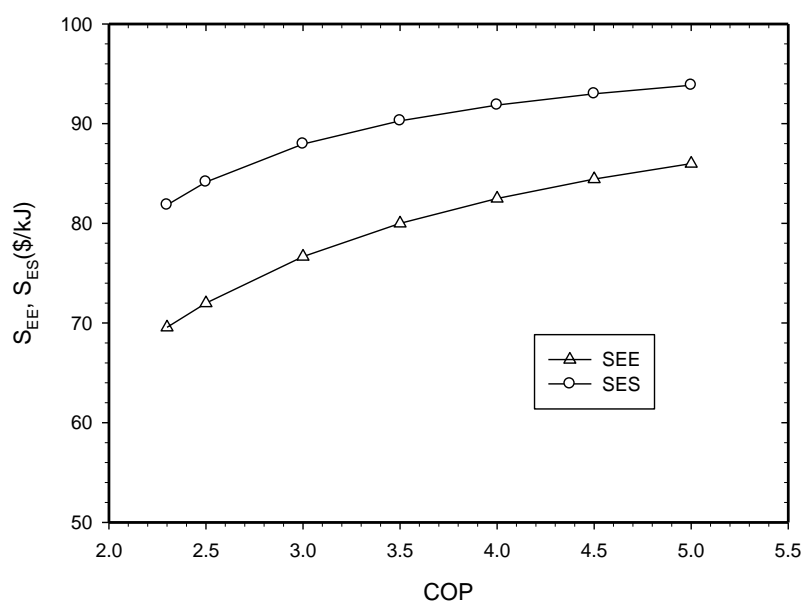

Fig. 11. Dependency of saving factor $\left(\mathrm{S}_{\mathrm{EE}}, \mathrm{E}_{\mathrm{ES}}\right)$ on coefficient of performance (COP).

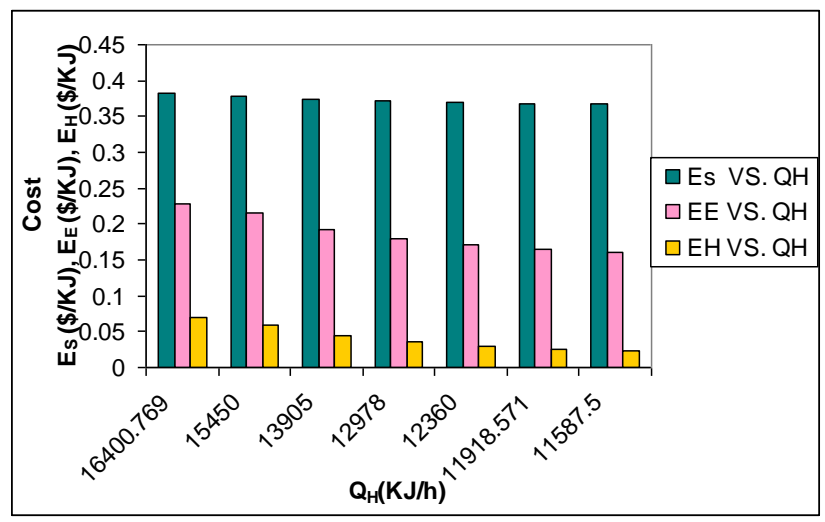

Fig.12. Cost of heating inlet air with: a-Heat pump b- Electrical heater and c- LPS steam in heater. 


\subsection{Case Two: AdDing heat PUMP ON OUTLET VAPOR LINE FROM CRYSTALLIZER}

The aim of this construction is to utilize and recovery heat content of the system by adding heat pump in three cases:

1. If the inlet to the evaporator (of heat pump) is outlet vapor from the crystallizer.

2. If the inlet to the evaporator is outlet steam from the jacket.

3. If the inlet to the evaporator is mixture of the outlet vapor from crystallizer and steam outlet from the jacket

The followings assumptions were proposed:

1. Steady state, steady flow operation.

2. Potential and kinetic energy effects are negligible

3. No chemical reaction.

4. Adiabatic compression efficiency is equal (0.7).

5. The price of electricity and low pressure steam for heating (LPS) are estimated to be 0.05 (\$/kW.h) and $3.17 \times 10^{-6}(\$ / \mathrm{kJ})$ respectively, and the cost of heating agent used in heater $=0.33 \$ / \mathrm{kJ} .[10]$

6. The used basis for calculation are listed in table (3) for $Q_{L}$ there are three value can calculate based on what is inlet to the evaporator of heat pump:

1 - If the inlet to the evaporator is steam $\mathrm{V}_{\mathrm{o}}$ at $\mathrm{T}_{4}=25^{\circ} \mathrm{Cand}$ out at $\mathrm{T}_{5}=12^{\circ} \mathrm{C}$

2- If the inlet to the evaporator is steam $\mathrm{S}$ at $\mathrm{T}_{4}=25^{\circ} \mathrm{Cand}$ out at $\mathrm{T}_{5}=12^{\circ} \mathrm{C}$

3- IF the inlet to the evaporator is steam V $\left(\mathrm{V}_{\mathrm{o}} \& \mathrm{~S}\right)$ at $\mathrm{T}_{4}=25^{\circ} \mathrm{Cand}$ out at $\mathrm{T}_{5}=12^{\circ} \mathrm{C}$. [See Figures(5), (6) $\&(7)]$

4- The used high-efficiency heat pump manufactured has COP of $(2.3-5)$ in the heating mode.[10].
The basis of calculation is presented in Table 3 .

TABle 3: BASIS FOR CALCULATIONS $[1,4]$

\begin{tabular}{|l|l|}
\hline $\mathrm{F}$ & $1000 \mathrm{Kg} / \mathrm{hr}$ \\
\hline $\mathrm{X}_{\mathrm{D}}$ & 0.6 \\
\hline $\begin{array}{l}\text { enthalpy of superheated steam } \\
\text { at }\left(75 \mathrm{kPa}, 150^{\circ} \mathrm{C}\right)\end{array}$ & $2778.2 \mathrm{KJ} / \mathrm{Kg}$ \\
\hline enthalpy of saturated steam at $\left(25^{\circ} \mathrm{C}\right)$ & $2547.2 \mathrm{KJ} / \mathrm{Kg}$ \\
\hline enthalpy of saturated steam at $\left(70^{\circ} \mathrm{C}\right)$ & $2626.8 \mathrm{KJ} / \mathrm{Kg}$ \\
\hline enthalpy of saturated steam at $\left(12^{\circ} \mathrm{C}\right)$ & $2523.4 \mathrm{KJ} / \mathrm{Kg}$ \\
\hline Latent heat of vaporization at $\left(70^{\circ} \mathrm{C}\right)$ & $2405.9 \mathrm{KJ} / \mathrm{kg}$ \\
\hline
\end{tabular}

The calculations of Flow rate of outlet steam from indirect crystallizer $V_{o}$, Flow rate of inlet steam fed to the jacket $S$, Heat accepted by evaporator $\mathrm{Q}_{\mathrm{I}}$, Work input of heat pump $\mathrm{W}_{\text {in }}$, Heat generated by condenser $\mathrm{Q}_{\mathrm{H}}$, Heat generated by heater without heat pump $\mathrm{Q}_{\mathrm{S}}$, and the amount of the heat that needed after preheating form heat pump $\mathrm{Q}_{\mathrm{J}}$ are presented in Table 4A. All the calculations are at constant feed concentration and the feed to heat pump evaporator consists of $S$ and $V_{0}$.

$4 \mathrm{~B}$ Shows the calculations of Total operating cost without heat pump $\Phi_{s}$; The total operating cost of heat pump $\Phi_{\mathrm{H}}$; The operating cost of the heat heating make up (after preheating by heat pump) $\Phi_{\mathrm{J}}$; the total operating cost of the process with a heat pump and heater $\Phi_{\mathrm{T}}$ and saving factor $S_{\mathrm{E}}$. All the calculations are at constant feed concentration and the feed to heat pump evaporator consists $S$ and $V_{0}$.

Figure 13 shows the three cases at value of COP lower than 3.5. The addition of heat pump is useless, because there is no saving (there is economical efficiency). But for values of COP higher than 3.5 the addition of heat pump gives noticeable saving and the saving factor is increased by increasing COP value. 
TABLE 4A: MATERIAL AND ENERGY BALANCES IN THE CASE OF ADDING HEAT PUMP ON OUTLET VAPOR LINE FROM CRYSTALLIZER

\begin{tabular}{|l|c|c|c|c|c|c|c|c|}
\hline COP & $\mathrm{X}_{\mathrm{F}}$ & $\begin{array}{c}\mathrm{V}_{\mathrm{o}} \\
(\mathrm{Kg} / \mathrm{hr})\end{array}$ & $\begin{array}{c}\mathrm{S} \\
(\mathrm{Kg} / \mathrm{hr})\end{array}$ & $\begin{array}{c}\mathrm{Q}_{\mathrm{L}} \\
(\mathrm{KJ} / \mathrm{hr})\end{array}$ & $\begin{array}{c}\text { Win } \\
(\mathrm{KJ} / \mathrm{hr})\end{array}$ & $\begin{array}{c}\mathrm{Q}_{\mathrm{H}} \\
(\mathrm{KJ} / \mathrm{hr})\end{array}$ & $\begin{array}{c}\mathrm{Q}_{\mathrm{s}} \\
(\mathrm{KJ} / \mathrm{hr})\end{array}$ & $\begin{array}{c}\mathrm{Q}_{\mathrm{J}} \\
(\mathrm{KJ} / \mathrm{hr})\end{array}$ \\
\hline 2.3 & 0.22 & 633.3333 & 6596.263 & 834427.2 & 641867.094 & 1476294.316 & 1523737 & 47442.35 \\
\hline 2.5 & 0.22 & 633.3333 & 6596.263 & 834427.2 & 556284.8148 & 1390712.037 & 1523737 & 133024.63 \\
\hline 3 & 0.22 & 633.3333 & 6596.263 & 834427.2 & 417213.6111 & 1251640.833 & 1523737 & 272095.83 \\
\hline 3.5 & 0.22 & 633.3333 & 6596.263 & 834427.2 & 333770.8889 & 1168198.111 & 1523737 & 355538.56 \\
\hline 4 & 0.22 & 633.3333 & 6596.263 & 834427.2 & 278142.4074 & 1112569.63 & 1523737 & 411167.04 \\
\hline 4.5 & 0.22 & 633.3333 & 6596.263 & 834427.2 & 238407.7778 & 1072835 & 1523737 & 450901.67 \\
\hline 5 & 0.22 & 633.3333 & 6596.263 & 834427.2 & 208606.8056 & 1043034.028 & 1523737 & 480702.64 \\
\hline
\end{tabular}

TABLE 4B: THE COST AND SAVING FACTOR IN THE CASE OF ADDING HEAT PUMP ON OUTLET VAPOR LINE FROM CRYSTALLIZER

\begin{tabular}{|c|c|c|c|c|c|}
\hline COP & $\begin{array}{c}\Phi_{\mathrm{s}} \\
(\$ / \mathrm{hr})\end{array}$ & $\begin{array}{c}\Phi_{\mathrm{H}} \\
(\$ / \mathrm{hr})\end{array}$ & $\begin{array}{c}\Phi_{\mathrm{J}} \\
(\$ / \mathrm{hr})\end{array}$ & $\begin{array}{c}\Phi_{\mathrm{T}} \\
(\$ / \mathrm{hr})\end{array}$ & $\begin{array}{c}\mathrm{S}_{\mathrm{E}} \\
(\$ / \mathrm{hr})\end{array}$ \\
\hline 2.3 & 5.160245 & 6.240374525 & 0.480392251 & 6.720767 & -30.2412 \\
\hline 2.5 & 5.160245 & 5.408324588 & 0.751688076 & 6.160013 & -19.3744 \\
\hline 3 & 5.160245 & 4.056243441 & 1.192543792 & 5.248787 & -1.71585 \\
\hline 3.5 & 5.160245 & 3.244994753 & 1.457057221 & 4.702052 & 8.879292 \\
\hline 4 & 5.160245 & 2.704162294 & 1.633399507 & 4.337562 & 15.94272 \\
\hline 4.5 & 5.160245 & 2.317853395 & 1.759358283 & 4.077212 & 20.98802 \\
\hline 5 & 5.160245 & 2.028121721 & 1.853827365 & 3.881949 & 24.772 \\
\hline
\end{tabular}

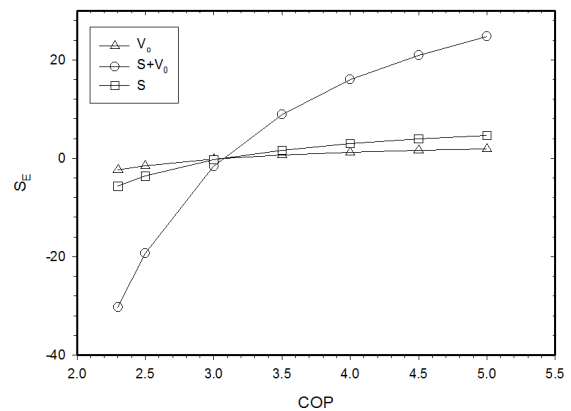

Fig.13. Dependency of saving factor on different heat pump coefficients of performance

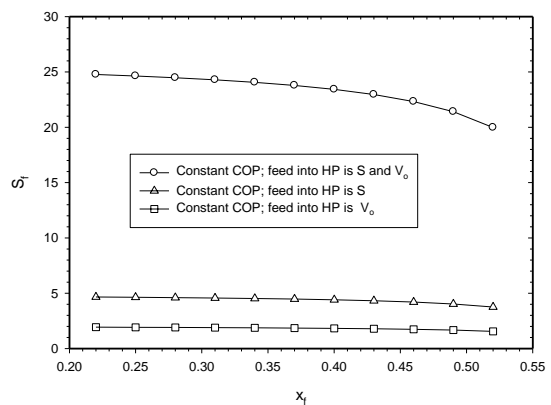

Fig.14. Variation of saving factor with different feed concentrations at constant $\mathrm{COP}$
Figure 14 is also shows the highest saving factor is achieved by addition of heat pump and mixing of steam from jacket and compressed vapor from crystallizer. It ranged from $8 \%$ to $25 \%$.

\section{CONCLUSIONS}

The heat saving in evaporative crystallization processes in the two types (direct and indirect evaporative crystallizers) is studied:

I. In case of direct evaporative crystallizer, a noticeable saving factor ranges between 69 to $86 \%$ and 81 to $93 \%$ based on electrical , steam heating respectively was achieved by adding heat pump with variable COP. The process of direct contact evaporative crystallization has an advantage of producing an additional amount of distillated water as byproduct of crystallization. 
II. In case of indirect evaporative crystallizer, a noticeable saving factor ranges between 8 to $26 \%$ based on steam heating was achieved by adding heat pump on outlet vapor line with variable COP. The process of direct contact evaporative crystallization has an advantage of producing an additional amount of desalinated water, when the main purposes of separation is extraction of minerals, comparing to traditional open solar pond evaporative systems.

\section{REFERENCES}

[1] Geankopolis, Christie J. Transport Processes and Unit Operations. 3rd Ed, Prentice Hall PTR, Englewood Cliffs, NJ, USA, 1993.

[2] M. Coulson and J.F. Richardson, "Chemical Engineering Volume 2: Unit Operations", 3rd. Ed., Pergamon Press, 1978.

[3] J. Mullin J.W., Crystallization, 3rd Ed., MPG Book, London, 2000.

[4] Perry, H. Robert, Green .W. Don, Perry's chemical engineer's handbook, MC Graw Hill, New York, 1999.

[5] Alan S. Foust, Leonard A. Wenzel, Curtis W. Clump, Louis maus, L. Bryce Andersen, Principles of Unit Operations , Bethlehem , Pennsylvania , 1960.

[6] Adnan M. Al-Harahsheh, Theoretical analyses of energy saving in a direct contact evaporative crystallization through the installation of heat pump, Desalination 251, 1-3 , 47-52, 2010 .

[7] Adnan M. Al-Harahsheh, A heat pump in a countercurrent crystallization process, Applied Thermal Engineering, 545-555, 2005.

[8] Adnan Al-Harahsheh, A heat pump in a direct contact evaporative crystallization: Can save energy Heat-set, Grenoble, France, 2005.

[9] Yunus A.Cengel Michael A. Boles, Thermodynamics An Engineering Approach ,5th Ed., MC Graw Hill, 2006.

[10] L. Ying, P.C. Flynn, Deregulated power price comparison of diurnal patterns, Energy Policy 32, 657-672, 2004. 


\section{توفير الطاقة في عمليات البلورة بالتبخير بإستخدام المضخة الحرارية}

$$
\text { زيد أحمد العنبر }
$$

جامعة البلقاء التطبيقية، كلية الهندسة التكنولوجية، عمان، المملكة الأردنية الهانثمية

(الملخص:

يقوم هذا البحث وبالاعتماد على الحسابات النظريه الى تقديم طرق مقترحه لتسخين المحلول فى كلا النوعين من عمليات البلوره بالتبخير. ان التصاميم المقترحه تهدف الى تقليل استهلاك الطاقه والتى بدورها نقلل التكاليف التشغيليه فى كلا النوعين من عمليات البلوره. ففي النوع الاول تم التوصل الى انه فى عملية التبخير المباشر وعندما تضاف المضخه الحراريه لتسخين الوسط (هو اء ساخن) تم توفير طاقه في مدى يتراوح بين 81\% 993\% عند قيم مختلفه لمعامل الاداء. وفى النوع الثانى (البلوره بطريقة التبخير غير المباشر) تم اضافة المضخه الحراريه على طول الخط الذي يحتوي على خليط من البخار الاتى من المبلور وبخار الماء الاتى من سترة التسخين والتى تشكل خليط يعمل كمصدر حراري للمضخه الحراريه ليقوم بتسخين اولي لبخار الماء الداخل الى سترة التسخين. لقد اظهرت الحسابات بانه تم توفير طاقه في مدى بتر اوح بين 8\% و26\% عند قيم مختلفه لمعامل الاداء. 